\title{
An Exploration of Corpus-Based Project-Oriented Innovative Experimental Teaching
}

\author{
Ping LIU ${ }^{1, a}$, Peng WANG ${ }^{2, b}$ \\ ${ }^{1}$ College of Foreign Languages, Huazhong Agricultural University, Wuhan, Hubei, 430070, China \\ ${ }^{2}$ College of Foreign Languages, Huazhong Agricultural University, Wuhan, Hubei, 430070, China \\ aliup@mail.hzau.edu.cn, bwangpeng@mail.hzau.edu.cn
}

Keywords: innovative experimental teaching (IET), corpus, project-oriented research

\begin{abstract}
Corpus represents a new tool and a new approach to linguistic research. It is used in innovative experimental teaching (IET). In this IET, English-major undergraduates are guided to do project research on linguistic features of agricultural academic English papers aimed at developing students' practical and innovative ability. Under the framework of constructivism learning theory, this study designs the teaching mode and procedures of the experimental teaching. One-semester IET witnesses the accomplishment of project research and the production of innovative research fruits. Students' comments on IET indicate that it achieves the purposes of improving students' multiple abilities, such as innovative ability and project research ability, and it is a supplement to theoretical teaching. This study aims to offer references for IET in the field of linguistics.
\end{abstract}

\section{Introduction}

In the year of 2007, the Project of Undergraduate Education Quality was launched by the Ministry of Education of China. This project attaches the greatest significance to the reform of experimental and practical teaching, as well as the cultivation of talents with abundant fundamentals, practical skills and innovative ability. Fu (2008) indicates that IET plays a vital role in higher education, and IET serves as a crucial approach to the cultivation of students' practical capability and innovative ability [1]. In recent years, much stress has been put on the cultivation of undergraduates' research ability and practical innovative ability. Traditionally, IET is associated with natural science disciplines. In fact, it is urgently needed in social sciences, such as economics, linguistics, etc. Research Project of Innovation Fund for undergraduates supported by the Chinese government and many Chinese universities is open to both natural sciences and social sciences majors. Statistics reveals that the research ability of undergraduates of foreign language majors is urgently calling for improvement. Furthermore, an increasing number of international competitions for undergraduates make high demands on undergraduates' research ability and innovative ability. Therefore, it is of great importance to conduct project-oriented IET aimed at enhancing undergraduates' research ability, which would facilitate the improvement of higher education quality.

\section{Basic Concepts of Corpus-Based IET}

IET employs the online agricultural corpus founded by Huazhong Agricultural University (HZAU). This corpus consists of sub-corpora of SCI (Science Citation Index) journal article corpus (5,537,109 words, 838 full texts) and learner paper corpus (1,845,286 words, 397 full texts) in the field of agriculture. The former represents the data from English native writers' published articles, while the latter collected English papers written by Chinese advanced learners majoring in agriculture. Both sub-corpora are structured in the same way with 9 discipline branches, such as agricultural economy, life science, animal science, food science, horticulture, etc. This agricultural corpus has been uploaded to HZAU CQPweb (web-based Corpus Query Processor (http://211.69.132.28/) open to university teachers and students on campus. IET utilizes HZAU CQPweb, aiming to help undergraduates conduct research projects examining linguistic features of 
agricultural English papers. Moreover, students' multifaceted abilities are also expected to be improved, such as research ability, innovative ability, thinking ability as well as the ability of problem discovery, problem analysis and problem solving.

IET involves three basic elements. (1) Students' practicality and teachers' autonomy. IET stresses students' practicality, focusing on students' engagement in and experience of the whole experiment process. IET is also characterized by the teacher's autonomy of experiment content, the exploration of experiment methods and the unpredictability of experiment results [2]. IET represents a transformation of the teaching view, teacher view, learning view, media view and teaching modes [3]. (2) Corpus as a resource, tool and method. Corpus is an electronic database of a large number of authentic language materials in the form of texts. As a resource and tool, corpus is widely used in language teaching and research due to its richness and authenticity of the collected language materials. Leech (1997) pointed out that corpus-based research represents a scientific method of language research due to the verifiability of research results with data from the corpus [4]. Language research based on corpus data has also been strongly recommended by some linguistic experts [5, 6]. (3) Innovative project-oriented research. Project-oriented research examines the unknown puzzles, utilizes innovative research methods, gains innovative research fruits, and ultimately aims to develop students’ creative thinking and innovative ability.

\section{Theoretical Basis of IET: Constructivism Learning Theory}

Constructivism learning theory has provided a solid theoretical foundation for IET. Based on constructivism, experimental teaching design reflects innovativeness in the following 3 aspects: (1) New teacher-student relationship with students as center and teachers as scaffolds. The research projects in the IET give the priority to students' independent learning and active exploration, converting teacher from the 'sage on the stage' to 'the guide on the side'. Teachers, acting as the organizer, tutor and facilitator, offer students necessary support and help during project research. (2) New learning concept focusing on students' independent investigation and collaborative learning. Since constructivism advocates that knowledge is constructed by learners themselves rather than imparted by teacher, experimental teaching provides students with opportunities to learn in groups and to construct knowledge based on the shared thoughts through project research. (3) New learning tools and method. Constructivism suggests that the mastery of knowledge and skills should be completed through students' active construction of meanings. Project-oriented experimental teaching requires students to employ corpus tool and method for knowledge innovation and construction and for the cultivation of innovative talents.

Under the framework of constructivism learning theory, an experimental teaching mode has been designed.

\section{Design of IET Mode}

Constructivism considers students as the active constructors of knowledge, teachers as the helper and facilitator, textbooks as the objects of knowledge construction and media as the cognitive tool. These four essential elements including students, teachers, textbooks and media in a new relationship form a particular teaching mode under the constructivism learning theory framework. In the real experimental teaching, students actively construct meanings and arrive at certain conclusions regarding the linguistic features of academic English papers for Science and Technology (EST). This whole process indicates the completion of knowledge construction. Self-constructed HZAU corpus of agricultural academic English papers (738 million words) and its online search platform, namely HZAU CQPweb are both research data and cognitive tools. Authorized users have free access to the online corpus platform, which provides the required network environment for project-oriented research. Details of this teaching mode are demonstrated by the following chart: 


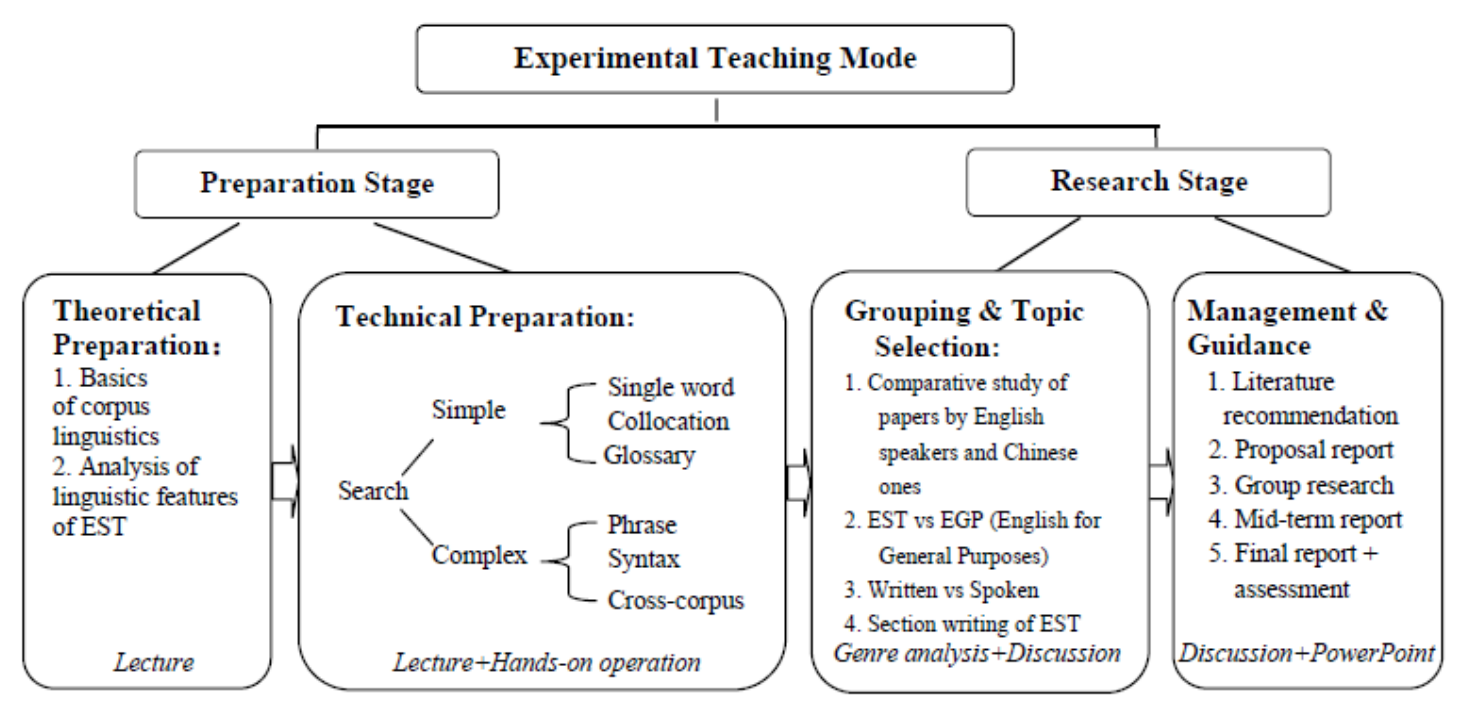

Teaching environment: computer lab + WiFi + online corpus platform

Teaching hours: 32 periods (45 min per period). Theory teaching ( 4 periods) + in-class corpus operation instruction (6 periods) + independent group project (16 periods) + in-class presentation (6 periods)

Students: junior and senior English-major undergraduates

\section{Teaching Practice of IET}

\section{Procedures of Project-Oriented IET}

Following the aforementioned teaching mode, one-semester IET (32 periods in total) was conducted. In this experimental course, 25 students were involved and each group of 5 people was offered a research topic to undertake the corresponding project. As the schema above illustrates, this experimental teaching consists of two stages: preparation stage and research stage. The former mainly focused on theoretical and technical instruction; the latter primarily concentrated on grouping, topic selection, paper writing and project report.

\section{Preparation Stage}

For the theoretical preparation, the teacher delivered lectures on basic theory and application of corpus linguistics, presenting the significant linguistic features of EST on the basis of corpus data analysis, such as nominalization, passive voice and impersonal subject, etc. In terms of the technical preparation, students were provided with systematic training on corpus search in a computer lab. More precisely, the teacher first gave a detailed introduction to the HZAU CQPweb as well as its online search structure and functions. Afterwards, instruction and practice were combined in order for students to perform search operation. A series of training on search was carried out on the progressive basis, from simple search to complex one; from single-corpus search to cross-corpus one; from guided search to independent one, and from completing search tasks given by the teacher to seeking answers to research puzzles found by students themselves. By means of three in-class computer operation practices and after-class corpus search practices, students have acquired the fundamental corpus operation skills.

\section{Research Stage}

This stage is mainly concerned with the following components: (1) grouping and topic selection. On a voluntary basis, 25 students were divided into 5 groups according to their research interest. Subsequently, each group autonomously determined one research topic from five topics provided by the teacher who helped students with the feasibility of their research. (2) Literature recommendation and research proposal guidance. According to the research topic determined by each group, the teacher recommended approximately 30 key references and also facilitated students 
to read more relevant references. With careful reading of at least 15 key references, each group started to undertake the research project design, and received targeted suggestions during the proposal presentation in class. (3) Independent research and mid-term report. After the proposal presentation, each group independently started to conduct the research project, in the process of which the teacher provided scaffolding and initiated a mid-term research report in class to guide each project. (4) Final report and assessment. With regard to the final assignment, each group was asked to hand in a research paper with 2000 to 3000 words, deliver a final report on the project and perform the oral defense. Finally, five groups all managed to complete the corresponding research project and turn in five research papers in total.

\section{Main Findings}

Innovative findings have been revealed in the following five aspects: (1) In terms of the research on the discourse distribution and discourse function of Limitation section in EST, it has been found that different positions of Limitation section exert different functions. (2) Regarding the comparative research on the lexicon of EST and that of general English, it has been revealed that lexicon of EST witnesses a higher degree of formality and abstractness, nominalization being a striking feature of EST. (3) As for the research on the syntactic differences of spoken and written language, it has been found that written language tends to use impersonal subjects which demonstrate objectivity and formality; instead, spoken language tends to use personal subjects which emphasize the construction of impersonal relationships. (4) In terms of the word choices of native English speakers and native Chinese speakers in the writing of EST, it has been revealed that English authors and Chinese authors have different choices of words. (5) There is a significant distinction between both authors in terms of the collocation of certain words.

In summary, through a series of research projects on a basis of corpus analysis, students have conducted comparative studies in such aspects as lexicon, syntax and discourse in the field of EST, and finally achieved innovative outcomes.

\section{Students' Evaluations of IET}

After this experimental course, semi-structured open-ended questionnaires were employed to collect students' comments on experimental teaching, project-oriented research and corpus-based learning method. The following are students' evaluations in detail.

(1) Experimental teaching. 1) This form of teaching has activated students' learning motivation to acquire new knowledge and skills by means of students' independent research and real practice. The teaching focus has shifted from knowledge impartment to ability cultivation. 2) Experimental teaching has also embodied multiple roles of the teacher acting as the organizer, facilitator, adviser and reviewer, who provided crucial management and inspection for research projects. 3) This innovative teaching mode places an equal stress on theory and practice. Not only have students gained the corpus operation skills but also have become skillful at analyzing language phenomena by utilizing the corpus data and pertinent theory. This presents the complementation of experimental teaching and theoretical teaching, which has achieved the dual objectives of knowledge impartment and ability cultivation.

(2) Project-oriented research. 1) Project-oriented research has enhanced students' research ability and practical skills, which have laid a foundation for their future research project application as well as academic paper writing and publication. 2) Innovative project-oriented research focuses on unexplored research puzzles, which have enabled students to develop their creative thinking and innovative ability. 3) Students' multiple abilities related to collaboration, critical thinking, and problem solving have been also elevated, by means of group discussion and cooperative work.

(3) Corpus-based learning method. 1) Corpus enjoys distinct merits which permit students to investigate linguistic features through both quantitative and qualitative analysis. 2) The big data of corpus tends to strengthen the research scientificity, contributing to a higher degree of credibility and validity of the research. 3) Corpus-based research attaches much importance to student-centered learning, which is conducive to the development of students' innovative ability. 4) Cross-corpus search and comparative studies also improved students' language sensitivity and deepened their 
understanding of linguistic features of EST. 5) Limitations. Corpus classification remains to be refined, with corpus data remaining to be enriched, and search method remaining to be simplified.

Apart from students' evaluations of IET, it is noteworthy that follow-up investigation should be conducted to study these students' future performance in language research project application, initiation and outcomes. In this way, the effectiveness of IET would be examined.

\section{Conclusion}

Project-oriented IET employs corpus as a learning tool and research method, guiding students to carry out language research. Under the framework of constructivism learning theory, this study has discussed the innovativeness of IET, namely new teacher-student relationship, new learning form, new learning method and tool. Based on this theory, an IET teaching mode has been established. With this teaching mode, one-semester experimental teaching was conducted, in which the teacher provided necessary support throughout the course, and five research projects were all completed with five major innovative findings. In addition, students' feedback on this experimental course were also collected, which signified the significant strengths of corpus-based research method, as well as positive effects of project-oriented research on the development of students' research and innovative ability. With self-constructed HZAU CQPweb, this study allows students to undertake the discourse analysis of EST through corpus approach. It can be argued that application of corpus tools and method caters to the demands of big data age, and facilitates the improvement of learners' innovative ability. This study is to provide references for relevant IET.

\section{Acknowledgement}

This research was financially supported by: 1. National Social Science Foundation Project of China (Grant NO. 14BYY162); 2. High Quality Research Paper Development Project funded by the Fundamental Research Funds for the Central Universities (Grant NO. 2662015PY193); 3. Key Courses Construction Project sponsored by Huazhong Agriculture University; 4. Team Building Project funded by College of Foreign Languages, Huazhong Agriculture University.

\section{References}

[1] FU Yanling, Understanding and thinking of making innovation experiments in university, J. Research and Exploration in Laboratory. 4 (2008) 12-15.

[2] WANG Guangyi, Experimental teaching thought and innovative ability cultivation, J. Research and Exploration in Laboratory. 8 (2008) 76-78.

[3] JIA Wei, LOU Liyuan, LUO Liping, Research and thinking of language experimental teaching in foreign language universities, J. Modern Educational Technology. 8 (2013) 87-89.

[4] G. Leech, Teaching and Language Corpora: A Convergence, Longman, London, 1997.

[5] M.A.K. Halliday., J.R. Martin, Writing Science: Literacy and Discursive Power, The Falmer Press, London, 1993.

[6] D. Biber., S. Conrad., R. Reppen, Corpus Linguistics: Investigating Language Structure and Use, Cambridge University Press, Cambridge, 1998. 